\author{
Mohammad Iqbal Khan ${ }^{1 *}$, Habib ur \\ Rahman $^{2}$ and Naveed Mufti ${ }^{3}$ \\ ${ }^{1}$ Department Surgery, Shifa International Hospital, \\ Shifa Tameer-e-Millat University Islamabad \\ Pakistan \\ ${ }^{2}$ Department of Cardiology, Shifa International \\ Hospital, Shifa Tameer-e-Millat University \\ Islamabad Pakistan \\ ${ }^{3}$ Pakistan Institute of Medical sciences Islamabad
}

Dates: Received: 07 September, 2016; Accepted: 30 September, 2016; Published: 04 October, 2016

${ }^{*}$ Corresponding author: Mohammad Iqbal

Khan, Professor of Surgery, Shifa International

Hospital, Shifa Tameer e Millat University, H-8/4,

Islamabad-Pakistan, Tel: +92 346444 9991; E-mail:

mikhandr@gmail.com; vc@stmu.edu.pk

www.peertechz.com

ISSN: 2455-5452

Keywords: Dmellitus; Ischemia; Vascular grafting; Diabetic foot; Patency of the graft

\author{
Research Article
}

\section{Patency of Reverse Saphenous Vein Graft for Revascularization of Lower Limbs in Diabetic Patients}

\begin{abstract}
Objectives: Diabetic patients are prone to early development of vasculopathy, resulting in lower limb ischemia, which can lead to non-healing ulcers, foot infection, loss of limb, and even death. These patients need revascularization of their limb either using endovascular or open surgical techniques. Not all patients are suitable for endovascular treatment warranting the open surgical revascularization techniques.
\end{abstract}

The objective of this study was to evaluate the patency of arterial bypass grafting using reverse saphenous vein graft in the treatment of peripheral vascular disease of the lower limbs in diabetic patients.

Patients and Methods: Between January 2004 and December 2014, 218 diabetic patients with lower limb ischemia of Fontaine class III and IV underwent distal arterial bypass grafting with autologous reverse saphenous vein graft. Another group of 103 patients where the saphenous vein was ether previously used or not suitable as conduit underwent revascularization using synthetic ePTFE graft. Patency of the grafts, overall effectiveness of revascularization, improvement in symptoms, and healing of ulcers were assessed at short-term (three months) and long-term (mean $20.6 \pm 6.6$ months) follow-up.

Results: At short-term follow-up, $88 \%$ of grafts were patent. Fifty-two percent of ischemic ulcers had healed, and severe ischemic symptoms (rest pain, claudication, ischemic ulcers, limitation of physical activities, and worsening of glycemic control) had improved or were resolved in $87 \%$ of patients. Compared to the synthetic graft group, $71 \%$ graft were patent on short term follow up. Amputation of a limb was required in $11 \%$ of patients even after revascularization. Renal impairment worsened, requiring renal transplantation, in $8 \%$ of patients who had undergone revascularization. Eight (4\%) patients died in long-term follow-up but none from complications of the revascularization.

Conclusions: A high percentage of autologous reverse saphenous vein grafts placed in diabetic patients with peripheral vascular disease are patent at long-term follow-up. The revascularization reduces the rates of amputation, helps in ulcer healing, and relieves ischemic symptoms. Comparing with the group of patients, where revascularization was achieved using synthetic grafts, a higher percentage patent grafts were found in autologous reverse saphenous vein grafts group.

\section{Introduction}

The clinical expression of vascular disease in the lower extremities of diabetics varies from asymptomatic to critical limb ischemia [1]. Ulcers and gangrene may develop, ultimately leading to amputation or even to death. In the diabetic population, the risk of vascular disease increases with age, duration of diabetes, and presence of peripheral neuropathy. The true prevalence of Peripheral Arterial Disease (PAD) in diabetics has been difficult to determine because most of the patients remain asymptomatic for various reasons, such as blunted pain perception because of the presence of peripheral neuropathy, and the lack of consensus on screening modalities for early diagnosis of PAD [2]. Due to the presence of high-risk cardiovascular disease, all patients with PAD should undergo clinical and diagnostic evaluations. Once PAD is diagnosed, further evaluation with Doppler studies, digital subtraction angiography, magnetic resonance angiography, and computerized tomographic angiography may be indicated [3]. In cases of critical ischemia of the limb, bypass surgery for limb salvage is an established treatment specifically in those patients who are not suitable endoluminal treatment or where endoluminal treatment has failed.

Revascularization is mandatory in all patients who have critical leg ischemia, incapacitating disease, or critical arterial stenosis with good distal run off; revascularization is possible whenever distal runoff is adequate. Revascularization may be achieved through endoluminal techniques or with surgical bypass [4]. Autogenous vein is the most effective conduit for infra inguinal arterial bypass procedures, especially for bypass to the infra popliteal arteries [5]. The synthetic graft is only used when autologous graft was either not available due one or the other reasons specifically in diabetics. More over the use of synthetic graft was prevented in the presence of diabetic foot infections [6]. In this study, 218 patients underwent surgical revascularization with autologous reverse saphenous vein graft and 103 patients with synthetic e PTFE graft. We assessed patency of the grafted conduit in the short term and yearly for up to five years, and assessed the outcomes of patient survival and limb salvage. 


\section{Patients and methods}

Between January 2004 and December 2014, a total number of, 636 patients with peripheral vascular diseases were operated at our institutions out of those 402 consecutive peripheral vascular bypass procedures were performed at our institutions on 218 diabetic patients with lower-limb ischemia of Fontaine class III and IV using autologous vein graft and 103 patients using synthetic ePTFE grafts. The guidelines of the European Consensus Document were applied to all patients [7]. Patients who had emergency operations, redo revascularization procedures, acute thromboembolic disease requiring emergency surgery, were not included in the study. Distal arterial bypass grafting with autologous reverse saphenous vein graft was used in 218 patients and in 103 patients synthetic ePTFE graft was used. Preoperatively, all patients were investigated with digital subtraction angiography or computerized tomographic angiography. All patients were operated under epidural or spinal anesthesia with prior anesthetist consultation. Before arterial clamping, 20003000 IU unfractioned heparin was administered to all patients. Postoperatively, all patients were given full-dose unfractioned heparin (20,000-40,000 IU/ 24 hours for three to five days, and thereafter were given acetylsalicylic acid at standard dose $(75 \mathrm{mg})$ daily. Peri-operatively apart from heparin and prophylactic antibiotics (cephalosporin third generation three doses as per hospital policy for clean wounds) and statins were prescribed to all patients, where antibiotics were continued when indicated (where there was diabetic foot infection or surgical site infections). The glycemic control was achieved during the peri operative period using standard insulin in divided doses as dictated by the regular blood glucose monitoring. All patients were reviewed in surgical clinics at six-month intervals for the first two years and yearly thereafter. Patency of grafts, overall effectiveness of the revascularization, improvement in symptoms, and healing of ulcers were monitored at short-term and long-term periods. Among the 321 diabetics, 158 (72.6) had postoperative conclusion-check angiograms; the others had Doppler studies. All patients were closely monitored for patency of their grafts, which was assessed by examination of peripheral pulses, ankle-brachial index, Doppler studies, or angiograms.

Results for quantitative variables were expressed as median \pm standard error, or as median and range; categorical findings were expressed as percentage (\%).

\section{Results}

Age and sex distribution of the patients are displayed in Table 1. Female patients tended to be younger than male patients. Patients' comorbidities are listed in Table 1. Fifteen patients with occluded bypass were treated successfully by thrombectomy. Six patients underwent major amputation after unsuccessful therapy within the hospital-stay period. The locations of the grafts and the type of bypass are given in Table 2.

Patients' short-term (three months) postoperative results were evaluated. The reverse saphenous vein grafts were patent in $88 \%$ $(192 / 218)$ of patients immediately after the procedure and at threemonths' follow-up. Compared to the synthetic graft group, $71 \%$ graft were patent on short term follow up. Amputation of a limb was required in $11 \%$ of patients even after revascularization. Two deaths (9.3\%) occurred in the short-term follow-up period. In patients in whom ankle-brachial index was measured, values of 0.8 and above were maintained in 55\%, of $0.6-0.8$ in $28 \%$, and less than 0.6 in $18 \%$. Reoperations were performed for graft thrombosis at the anastomosis sites in six (2.8\%) patients and for hematoma in nine (4.1\%) patients.

Mean long-term follow-up time was $20.6 \pm 6.6$ months. At that time, $162(74 \%)$ of the 218 diabetics were physically active, with enhanced quality of life (overall effectiveness of revascularization) compared to their preoperative state; grafts were patent in 163 (75\%) patients compared to the synthetic group where on long term follow up graft were patent in 61 (59\%) patients. Eight patients (4\%) had died. The causes of death were myocardial infarction (five), end-stage renal disease and renal failure (one), recurrent stroke (one), and complications of renal transplantation (one); no death was due to complications of the revascularization.

Among patients who had ischemic ulcers, $52 \%$ of the ulcers had healed, and $87 \%$ of patients who had ischemic symptoms (rest pain, claudication, ischemic ulcers, limitation of physical activities, and worsening of the glycemic control) had relief of symptoms. Amputation of a limb was required in 24 (11\%) of patients even after revascularization. The site and side of the amputations are given in Table 3.

Diabetes was better controlled in $73 \%$ of patients on short-term and long-term follow-up, whereas renal impairment worsened, requiring renal transplantation in $8 \%$ of patients after revascularization for limb ischemia.

\section{Discussion}

In this study, we evaluated the patency rate of vascular conduit, limb salvage, overall effectiveness of revascularization, improvement in symptoms, and healing of ischemic ulcers in diabetic patients who

\begin{tabular}{|l|l|l|}
\hline \multicolumn{3}{|l|}{ Table 1: Age and sex distribution with Co-morbidities in the 218 diabetic patients. } \\
\hline Age Group (Years) & Male & Female \\
\hline $\mathbf{3 0 - 3 9}$ & 5 & 0 \\
\hline $\mathbf{4 0 - 4 9}$ & 23 & 4 \\
\hline $\mathbf{5 0 - 5 9}$ & 37 & 13 \\
\hline $\mathbf{6 0 - 6 9}$ & 78 & 17 \\
\hline $\mathbf{7 0 - 7 9}$ & 26 & 5 \\
\hline $\mathbf{8 0}$ and above & 7 & 3 \\
\hline Total & 176 & 42 \\
\hline
\end{tabular}

Table 2: The Type of revascularization and location of reverse saphenous vein grafts in the 218 diabetic patients

\begin{tabular}{|l|c|c|}
\hline Surgical procedure & Patients & $\%$ of Subtotal \\
\hline Femoro-popliteal bypass above knee & 87 & $40 \%$ \\
\hline Femoro-popliteal bypass below knee & 105 & $48 \%$ \\
\hline Femoro- posterior tibial bypass & 17 & $8 \%$ \\
\hline Femoro- peroneal bypass & 09 & $4 \%$ \\
\hline Total & 218 & $100 \%$ \\
\hline
\end{tabular}


Table 3: Site and side of amputations in the 218 diabetic patients who underwent revascularization.

\begin{tabular}{|l|l|l|l|}
\hline Amputation site & Right & Left & Rehabilitation \\
\hline Great toe & 2 & 1 & Satisfactory \\
\hline Other toes & 2 & 2 & Satisfactory \\
\hline Midtarsal & 4 & 1 & Adequate \\
\hline Syme & 1 & 0 & Adequate \\
\hline Below knee & 4 & 6 & Adequate \\
\hline Above knee & 1 & 0 & Inadequate \\
\hline Total & 14 & 10 & n/a \\
\hline
\end{tabular}

had undergone autologous reverse saphenous vein grafting. The major findings were the following: at long-term follow-up, grafts were patent in $88 \%$ of patients; $52 \%$ of ischemic ulcers had healed; and severe ischemic symptoms (pain at rest, claudication, ischemic ulcers, limitation of physical activities, and worsening of glycemic control) had improved or resolved in $87 \%$ of patients. Amputation of a limb was required in $11 \%$ of patients even after revascularization, a rate similar to that in other studies but much lower than the $46 \%$ $62 \%$ rate of amputation in patients with critical limb ischemia treated conservatively [8]. Renal impairment worsened, requiring renal transplantation, in $8 \%$ of patients. At long-term follow-up, although $4 \%$ of patients had died, none died from complications of the revascularization. Overall, the results indicate substantial improvement in the vascular consequences of PAD in most of the diabetic patients. The venous conduit we used for revascularization had better outcomes (long-term patency of the graft, limb survival, and symptomatic improvement) than outcomes reported for synthetic grafts, especially in patients with below-knee outflow anastomoses [9].

The global burden of diabetes is projected to increase to over 380 million people by the year 2025 [10]. PAD is an important risk factor for lower extremity amputation in diabetic patients, especially those with foot ulcers. In patients with severe leg ischemia, revascularization has been reported to produce a better quality of life than does amputation [11]. Evolution and refinement of vascular surgical techniques have significantly improved limb preservation and decreased the incidence of lower-extremity amputation [12]. Diabetic patients are at high risk for loss of limbs due to neuropathy, infection, and the presence of arterial occlusive disease. The prevalence of PAD in diabetic persons, as in others, differs in various geographic zones around the globe [13].

Successful revascularization of ischemic limbs in diabetic patients reduces the rate of major amputation [14]. Revascularization can be achieved either with surgical bypass or endoluminal procedures. PAD presents as intermittent claudication and absence of peripheral pulses in the lower limb or pain at rest. Chronic limb ischemia is the most severe phase of PAD, with loss of limb being a dreaded consequence. In the Western world, the prevalence of symptomatic peripheral arterial occlusive disease causing intermittent claudication in men and women aged $55-74$ years is $45 \%$; diabetics are twice as susceptible to these complications as are non-diabetic persons [15]. The clinical manifestations of atherosclerosis occur primarily in three vascular beds: coronary arteries, lower limbs, and extra cranial carotid arteries. Diabetes increases the incidence of atherosclerosis and accelerates the atherosclerosis of each vascular bed. Diabetics have a 2- to 4-fold higher rate of PAD than do non-diabetics with similar other risk factors [16]. Both the duration and severity of diabetes correlate with the incidence, extent, and severity of PAD. Diabetes also alters the course and nature of infra popliteal arterial occlusive disease and vascular calcification are more common in diabetics than in non-diabetic cohorts [17]. Moreover, diabetics more frequently develop the symptomatic forms of PAD disease, such as intermittent claudication and loss of limbs compared to nondiabetics $\mathrm{f}$ similar risk group. The presence of diabetes reportedly increases the risk of claudication by 3.5 fold in men and 8.6 fold in women [15]. Uncontrolled and longstanding diabetes is the cause of most non traumatic lower extremity amputations in the United States [18].

The only way to alleviate symptoms and prevent the loss of limbs in patients with critical limb ischemia is revascularization. Methods of revascularization and their applicability are a matter of discussion. The saphenous vein has been widely used as conduit [19] And the reverse saphenous vein graft is considered the best method of revascularization [20]. The reported global quality of life after revascularization was similar in our study (74\%) and previous studies (69 to $75 \%$ ), and the long-term patency of the saphenous vein grafts also was similar ( $75 \%$ vs $72 \%$ ). However, we prefer to use saphenous vein grafts because of their excellent reported patency and because the available contra-lateral vein can be harvested [21]. which allows the procedure to be applied to more patients.

End-stage renal disease is a strong risk factor for foot ulceration and amputation in diabetics. This and other risk factors accentuate the difficulties in planning treatment, and the long-term mortality rate is high. The risk factors may negatively influence the decision to perform a revascularization procedure [22]. However, our data indicate that even patients with increased risk factors may have favorable results [23]. Our study further establishes the advantages of early revascularization in diabetic patients who have critical limb ischemia requiring revascularization. The patency of the conduit depends on the status of the grafted vessel, the distal run off, the status of the proximal feeding vessels, and glycemic control [24]. Although numerous studies have assessed the patency of vein grafts in diabetic and non-diabetic patients, few studies have been conducted solely in diabetics [25]. In agreement with another study, our results support the view that diabetes has no negative impact on the patency of vessels in peripheral bypass operations. Except for the increased mortality during follow-up in diabetics, the clinical result (limb salvage and healing of pedal lesions) in patients with and without diabetes seems to be similar; the latter result was demonstrated for the first time in this study. Surely the outcomes in this study represent only a first step in assessing the overall outcome of revascularization of peripheral vessels in diabetic subjects; more investigations will be needed to determine the function of preserved feet and the duration of healing achieved.

\section{Conclusion}

Peripheral vascular disease is a serious problem in diabetic patients, resulting in increased mortality and morbidity if not treated effectively. Distal arterial revascularization, using reverse saphenous 
vein graft, is proved to be an effective surgical technique that reduces the rate of amputation, helps in ulcer healing, and relieves ischemic symptoms as the graft remained patent in majority of the cases at long-term follow up in these patients. Comparing with the group of patients, where revascularization was achieved using synthetic grafts, a higher percentage patent grafts were found in autologous reverse saphenous vein grafts group.

\section{Ethical consideration}

Ethical approval to conduct the study was obtained from the Institutional Review Board before the commencement of the study. Written informed consent was obtained from the patients for the publication of this report.

\section{Authors' Contributions}

Mohammad Iqbal Khan carried out conception and design, acquisition of data, analysis, interpretation, and writing manuscript Habib Ur Rahman and Naveed Mufti carried out drafting and reviewing the manuscript. All authors read, critically reviewed, checked the final version and approved the final manuscript. Both the authors are accountable for all aspects of the work presented to Journal- Vascular for peer review and publication. All authors ensure that questions related to the accuracy or integrity of any part of the work are appropriately investigated and resolved.

\section{Disclaimer}

We declare that this work was never presented in any conference or symposia nationally or internationally other than periodical presentations during the grand rounds and in departmental meetings of the hospital. This work was never published in any form: electronic or print in any journal, periodicals, or conference proceedings etc. prior to sending it for peer review to international journal vascular surgery and Medicine.

\section{References}

1. Bradbury AW, Adam DJ, Bell J, Forbes JF, Fowkes FG, et al. (2010) Multicenter randomized controlled trial of the clinical and cost-effectiveness of a bypass-surgery-first versus a balloon-angioplasty-first revascularization strategy for severe limb ischaemia due to infra inguinal disease. The Bypass versus Angioplasty in Severe Ischaemia of the Leg (BASIL) trial. Health Technol Assess. 2010; 14: 1-210.

2. American Diabetes Association (2003) Peripheral arterial disease in people with diabetes. Diabetes Care. 2003; 26: 3333-3341.

3. Suzuki K, lida O, Yamauchi Y, Nakano M, Soga Y, et al. (2013) Impact of diabetes mellitus on critical limb ischemia with below the knee disease: Japan Below-the-knee Artery Treatment Sub analysis. Angiology.

4. Nguyen LL, Moneta GL, Conte MS, Bandyk DF, Clowes AW, et al. (2006) Prospective multicenter study of quality of life before and after lower extremity
vein bypass in 1404 patients with critical limb ischemia. J Vasc Surg 44: 977983.

5. Pomposelli FB, Kansal N, Hamdan AD, Belfield A, Sheahan M, et al. (2003) A decade of experience with dorsalis pedis artery bypass: analysis of outcome in more than 1000 cases. J Vasc Surg 37: 307-315.

6. Klinkert P, Schepers A, Burger DH, van Bockel JH, Breslau PJ (2003) Vein versus polytetrafluoroethylene in above-knee femoropopliteal bypass grafting: five-year results of a randomized controlled trial. J Vasc Surg 37: 149-155
7. Norgren L, Hiatt WR, Dormandy JA, Nehler MR, Harris KA (2007) InterSociety Consensus for the Management of Peripheral Arterial Disease (TASC II). J Vasc Surg 33: S5-S67.

8. Faglia E, Clerici G, Clerissi J, Gabrielli L, Losa S, et al. (2006) Early and five-year amputation and survival rate of diabetic patients with critical limb ischemia: data of a cohort study of 564 patients. Eur J Vasc Endovasc Surg 32: 484-490.

9. Reiber GE, Lemaster JW (2008) Epidemiology and economic impact of foot ulcers and amputation in people with diabetes. In: Bowker JH, Pfeifer MA, editors. Levin and O'Neal the diabetic foot. 7th ed. Philadelphia: Mosby 3-22.

10. Dolan NC, Liu K, Criqui MH, Greenland P, Guralnik JM, et al. (2002) Peripheral artery disease, diabetes, and reduced lower extremity functioning. Diabetes Care 25: 113-120.

11. Pell JP, Donnan PT, Fowkes FG, Ruckley CV (1993) Quality of life following lower limb amputation for peripheral arterial disease. Eur J Vase Surg 7: 448451.

12. Hallett JW Jr, Byrne J, Gayari MM, Ilstrup DM, Jacobsen SJ, et al. (1992) Impact of arterial surgery and balloon angioplasty on amputation: a population-based study of 1155 procedures between 1973 and 1992. J Vasc Surg 25: 29-38.

13. Hamden A, Pomposelli F (2008) Lower limb arterial reconstruction in patients with diabetes mellitus: Principles of treatment. In: Bowker JH, Pfeifer MA, edeitors. Levin and O'Neal's the diabetic foot. 7th ed. Philadelphia: Mosby 429-442.

14. Simms M (2006) Peripheral vascular diseases and reconstruction. In: Boulton AJM, Cavanagh PR, Rayman G, editors. The Foot in Diabetes. 4th ed. Chichester, UK: Wiley 250-264.

15. Jude EB, Oyibo SO, Chalmers N, Boulton AJ (2001) Peripheral arterial disease in diabetic and non-diabetic patients. Diabetes Care 24: 1433-1437.

16. Kannel WB, McGee DL (1985) Update on some epidemiologic features of intermittent claudication: the Framingham Study. J Am Geriatr Soc 33: 13-18.

17. Centers for Disease Control and Prevention (CDC) (1998) Diabetes-related amputations of lower extremities in the Medicare population-Minnesota, 1993-1995. MMWR Morb Mortal Wkly Rep 47: 649-652.

18. Hinchliffe RJ, Andros G, Apelqvist J, Bakker K, Friederichs S, et al. (2012) A systematic review of the effectiveness of revascularization of the ulcerated foot in patients with diabetes and peripheral arterial disease. Diabetes Metab Res Rev 28: 179-217

19. Taylor LM Jr, Edwards JM, Porter JM (1990) Present status of reversed vein bypass grafting: five year results of a modern series. J Vasc Surg 11: 193206.

20. Zhu YQ, Zhao JG, Liu F, Wang JB, Cheng YS, et al. (2009) Subintimal angioplasty for below the ankle arterial occlusions in diabetic patients with chronic critical limb ischaemia. J Endovasc Ther 16: 604-612.

21. Ruiter MS, van Golde JM, Schaper NC, Stehouwer CD, Huijberts MS (2010) Diabetes impairs arteriogenesis in the peripheral circulation: review of molecular mechanisms. Clin Sci (Lond) 119: 225-238.

22. Hertzer NR, Bena JF, Karafa MT (2007) A personal experience with the influence of diabetes and other factors on the outcome of infrainguinal bypass grafts for occlusive disease. J Vasc Surg 46: 271-279.

23. Ndip A, Lavery LA, Boulton AJ (2010) Diabetic foot disease in people with advanced nephropathy and those on renal dialysis. Curr Diab Rep 10: 283290.

24. Slim H, Tiwari A, Ritter JC, Rashid H (2011) Outcome of infrainguinal bypass grafts using vein conduit with less than 3 millimeters diameter in critical leg ischemia. J Vasc Surg 53: 421-425.

25. Prompers L, Schaper N, Apelqvist J, Edmonds M, Jude E, et al. (2008) Prediction of outcome in individuals with diabetic foot ulcers: focus on between individuals with and without peripheral vascular disease. The EURODIALE Study. Diabetologia 51: 747-755. 